\title{
La dietética en la conquista de sí
}

\section{The dietetics in the conquer of the self"}

\author{
ANA CAMPOS ISLA \\ Universidad Iberoamericana \\ Ciudad de México, México
}

anasofit12@hotmail.com

Artículo de investigación

Recepción: 14 de enero de 2020

Aceptación: 26 de marzo de 2020

Como citar este artículo

Campos, S. (2019). La dietética en la conquista de sí.

Sosquua 1(2), pp.35-43. Recuperado a partir de: http://cipres.

sanmateo.edu.co/index.php/sosquua 
Figura 1. Pintura de una figura humana disuelta; refiere a la subjetividad del hombre contemporáneo

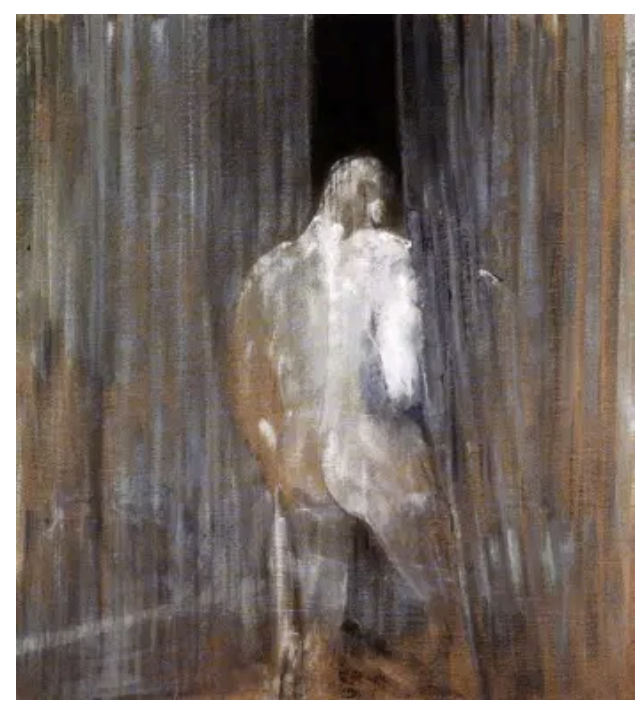

Fuente: Bacon, F., "Study from the human body", 1949.

\section{Resumen:}

Este artículo propone revisar, señalar y determinar la importancia de las posturas dietéticas en el siglo actual, a partir de dos (2) pensadores claves. El primero es Plutarco y el texto Cómo mantenerse sano. El segundo es Friedrich Nietzsche, en particular, los primeros dos (2) apartados de Ecce Homo. El texto también introduce a la reflexión sobre ideas principales del discurso psicoanalítico, diferente al filosófico; por su incidencia en la lectura y en el trabajo clínico en lo que acontece con los sujetos en relación con el cuerpo actualmente. Finalmente, esboza algunas divergencias y encuentros entre estos discursos.

Palabras Clave: postura dietética; Plutarco; Nietzsche; psicoanálisis; cuerpo. 


\begin{abstract}
:
This article proposes to review, point and decide the value of the dietetic positions in the actual century, from two (2) key thinkers. The first one is Plutarch and his text "How to Stay Healthy". The second one is Friedrich Nietzsche, in particular, the two principals Ecce Homo sections.This paper also introduces the reflection about the main ideas of the psychoanalytic discourse, different from philosophical; due to its incidence in the reading and in the clinic work about the subjects in connection with the body. Finally, this paper sketches out some divergences and meetings between this discourses.
\end{abstract}

Keyword: dietetic position; Plutarch; Nietzsche; psychoanalysis; body.

\title{
Introducción
}

"...de todos los bienes que la preciosa y deseada salud puede dar, el más preciado es la libertad para la adquisición de la virtud y para su uso tanto en las palabras como en los hechos".

Plutarco

La dietética para Plutarco y Friederich Nietzsche es entendida como el camino que lleva al dominio de sí. Es originado en el conocimiento del cuerpo propio, sin embargo, no es solo esto. Para Plutarco, pensar la salud fue un asunto de filósofos y no exclusivamente de los médicos porque el cuerpo es la morada, el lugar más entrañable e íntimo.

La medicina ocurre en el tiempo de Plutarco (81 d.C.); una ciencia en auge que atesoraba una parte de los conocimientos que permiten bienestar al cuerpo. La otra parte de este conocimiento le correspondía a los filósofos; antes que la medicina, ellos reflexionaban sobre lo ético y lo estético en la dieta, así como sus efectos en la vida de los hombres; incluso a algunos los aconsejaban personalmente.

Las cuestiones filosóficas y sociales en este campo son amplísimas y recorren distintos niveles de la experiencia: ¿Cómo responder con moderación ante los 
festejos sociales?, ¿Cómo organizar un banquete?, ¿De qué temas hablar en un banquete?, ¿Qué alimentos y actividades nos vuelven más inteligentes?, ¿Cuánto tiempo dedicarle al movimiento y a las actividades intelectuales?, ¿Qué leer?, ¿En qué clima vivir?, ¿A qué hora y con cuánta frecuencia es recomendable procurar los placeres amorosos? ¿Se deben permitir los excesos?, ¿Con cuánta frecuencia?, ¿Cuánta hidratación requiere el cuerpo?, ¿Cómo debe comer y vivir alguien que tiene la responsabilidad de gobernar a otros?

La postura de Plutarco sugiere moderación de los placeres para poder recibirlos constantemente; la enfermedad, causada por los excesos o el descuido, priva al cuerpo de recibir más placeres. Esta regulación tiene por objetivo prevenir y mantener al cuerpo en un estado siempre óptimo. Para ello se requieren tres (3) aspectos: dominio de sí, conocimiento de las propiedades de los alimentos y bebidas, más los conocimientos de los comportamientos adecuados en los ámbitos sociales.

En cuanto a los alimentos señalados como "buenos", se encuentran los que no están demasiado sazonados y aquellos familiares para cada individuo; no los exóticos o que causan indigestión. El agua es importante para mantener el cuerpo sano y ligero, sobre todo, después de una borrachera o un esfuerzo físico agotador. Por otro lado, el placer que pueden proporcionar las actividades amorosas y alimenticias depende de la salud y el estado de la carne del cuerpo.

Plutarco (2018) se sirve de términos como limpieza, ligereza o calma para referirse a los estados ideales que pueden producir deleites en el cuerpo. La gran virtud para Plutarco es la moderación cotidiana; conduce al dominio de sí, en contra de la esclavización de los placeres a la que los hombres están tentados a subyugarse. Reconoce y sugiere el interés y la dedicación por la cultura como antídotos contra apetitos desmedidos. Sabe que para los dedicados al mundo de las letras, los ejercicios intelectuales son parte de la alimentación; tiene efectos en el cuerpo, incluso después de cenar, estas actividades ayudan a la digestión. En estas afirmaciones elucida que lo que pasa en el espíritu (psique), correspondiente a los procesos del cuerpo (soma), de forma inseparable.

En la misma dietética Plutarquiana, la variación de los alimentos es recomendada para el bienestar espiritual y físico; también realizar actividades diversas constantemente. En consecuencia, ligereza no implica la exaltación del ocio. Como se menciona en anteriores párrafos, el bienestar espiritual está unido al corporal, por lo tanto, el alma no debe abusar del cuerpo para realizar sus 
intereses; por ejemplo, el estudio puede ser excesivamente celoso del tiempo y volver sedentarias a las personas.

En este sentido, un punto importante del pensamiento de Plutarco sobre el dominio de sí corresponde a la indicación según la cual antes de buscar medicamentos, o requerir la ayuda de un médico, una persona debe dominar los conocimientos de las propiedades de los alimentos y sus efectos para la digestión. Lo anterior, con el fin de prevenir y curar las enfermedades.

"...cada uno debe conocerse a sí mismo y las peculiaridades de sus pulsaciones (Pues hay muchas diferencias en cada uno), y no desconocer la mezcla de calor y sequedad que tiene el cuerpo, ni las cosas cuyo uso puede resultar útil o dañino, ya que es un hombre que se conoce a sí mismo y vive ciego y sordo en su propio cuerpo el que conoce estas cosas por otro y pregunta al médico si está más sano en verano, que en invierno, si tolera mejor los líquidos o los sólidos y si tiene por naturaleza un pulso acelerado o débil." (Plutarco, 2018, p. 165)

Este escrito de Plutarco fue dirigido a políticos y hombres de letras; ocupaciones que implican altas intensidades de trabajo intelectual. Por un lado, permiten moderar los placeres; por el otro, propician el descuido del cuerpo.

Ahora bien, varios siglos más adelante Friederich Nietzsche, a los 44 años, elaboró un texto para contarse su vida y entender cómo había llegado a ser él, y a producir su obra. Entre todas las preocupaciones del ser humano, elige la de la dietética ¿por qué? La alimentación produce el vigor de la vida y lleva a los hombres a obtener la fuerza o la debilidad para alcanzar la elevación del espíritu.

Durante su vida padeció diversas enfermedades; lo llevaron a tener una consciencia aguda sobre lo que pasaba con su cuerpo y pensamiento, en un estado físico al que llamó decadente o mínimo. A partir de lo anterior, concluyó que vivir los estados contrarios, de salud y enfermedad, agudiza la sensibilidad ante lo bello y lo terrible. Gracias a esto, tomó la enfermedad como motor para crear su filosofía vital, con la que propuso lograr la mayor realización posible de la voluntad.

La enfermedad lo llevó a entender de forma similar a lo expuesto por Plutarco en el texto Cómo mantenerse sano: conocer la propia morada resulta ser lo fundamental para alcanzar calidad de pensamiento, además de una variada experimentación de los placeres. Esto es, ser su propio médico para no necesitar acudir a uno; cuidarse, conocerse y saber alimentarse, es lograr la conquista de sí. 
Lo que Nietzsche consideró verdaderamente importante fue casi ignorado por los pensadores de los últimos siglos; centrados en temas espirituales y morales. Él re-descubrió que la comida, el clima, el lugar en el que vivimos, las formas de recreación, los ejercicios físicos, el tipo de lecturas que hacemos, son los elementos que producen cierto tipo de pensamiento y carácter, en conjunto.

Parece un descubrimiento simple, pero en ese tiempo la humanidad creía más importante pensar en Dios, el alma, el más allá, la vida eterna, y otras cuestiones que excluían lo mundano. Así, el problema inscrito en tono de exaltación por Nietzsche, es consecuencia de la jerarquía que le otorgó la religión cristiana a la espiritualidad, por encima de lo corporal.

Es pertinente preguntarse si este tratamiento religioso del soma no es la causa que llevó al extravío de la sabiduría sobre la dietética; completamente relegada al plano médico y no al filosófico. Entonces, ¿Qué lugar tienen los sabios en el siglo XXI? La pérdida ha eximido al sujeto de preguntarse sobre la morada que es su cuerpo, y lo volvió estéril en la creación de su singularidad y la de otros.

Otro punto fuerte del pensamiento de Nietzsche es que la salud no es lo mismo que entendemos en el siglo XXI; su idea va más allá del puro cuerpo biológico. La dirige a la fuerza de otro cuerpo, el cuerpo psíquico: el músculo para gobernarse. Algunas de sus recomendaciones dietéticas son: seguir la dieta mediterránea, permite una buena digestión; tomar agua más que vino, pues el vino estaba relacionado a la liturgia cristiana, y Nietzsche era crítico de las ideas de esta religión.

Además, sugiere comer grandes comidas para hacer trabajar al estómago, con el fin de probar y ejercitar su capacidad. Recomienda el movimiento frecuente; se desarrollan otra clase de pensamientos de acuerdo con la posición y estado del cuerpo. Otro punto que define su dietética es escoger vivir en un clima que ayude al metabolismo. En palabras de Nietzsche (2005), "El metabolismo le da ritmo al espíritu" (p. 45).

Los textos de Nietzsche y Plutarco son similares en el planteamiento del cuidado y conocimiento de sí: en la moderación de los placeres; piensan en el cuerpo y el alma como una unidad inseparable; ambos recomiendan buscar el tipo de alimentos que propician la ligereza, el cuidado de las actividades intelectuales y el rechazo a la vida sedentaria. 
Cada uno hace su propuesta filosófica desde lo racional; extraíble de sus experiencias, como testimonios que buscan desenredar el desorden sobre lo real del soma, es decir, lo no-subjetívable existente en los cuerpos. En este punto es pertinente introducir un cambio de registro a las construcciones psicoanalíticas sobre el cuerpo y su constitución histórica.

En el siglo XXI, el discurso por excelencia en asuntos de salud y dieta es el de la medicina, distanciada de la indagación filosófica o psicológica. Las personas que quieren saber algo sobre su alimentación lo hacen por alguna falla en la salud física o para responder a un imperativo contemporáneo sobre su imagen. Entonces los sujetos buscan a otro que le suponen saber más de los cuerpos.

Sin embargo, la cuestión es que el cuerpo de la medicina es un cuerpo del signo físico; considerado solo en su aspecto biológico y por lo tanto igual a otros, de subjetivado, sin historia; es la alienación del cuerpo de los sujetos por parte del discurso médico, sustentado por el capitalismo. Este discurso niega un lugar de reconocimiento al deseo del sujeto; lo enajena al quitarle singularidad a su padecimiento o necesidad alimenticia. Sobre todo, quita un sentido y un saber propio sobre sí mismo.

Algunos sujetos acuden también al psicólogo o al psicoanalista en busca de un saber, pero el psicoanálisis se opone a responder con la lógica del discurso amo; aquel que pretende poseer las respuestas sobre el otro, ante las demandas de un saber en sentido inverso, es decir, de aquel que pregunta. Hablar sobre dietética relaciona las prácticas del cuerpo, pero también de más allá del cuerpo, tema a resolver por el psicoanálisis.

¿Qué es lo que el psicoanálisis hace con el cuerpo? Su interés no es el conocimiento biológico ni médico del cuerpo; tampoco se asemeja a prácticas corporales como el yoga o la gimnasia, pero reconoce su importancia como técnicas del significante Amo, es decir, tratan de introducir al cuerpo en un orden. Incluso el discurso filosófico de una propuesta dietética puede ubicarse en el lugar del Amo; no quiere decir que no sea valioso y necesario en la construcción subjetiva, sin embargo, es otro tipo de lógica a la del psicoanálisis.

Esta disciplina, fundada por Freud y seguida principalmente por Lacan, piensa el registro de lo alimenticio determinado por la pulsión oral; sigue la lógica del deseo: no hay un objeto fijo, ni siquiera más recomendable. Existe una relación 
particular con los objetos, significan algo más allá de sí mismos; hay obediencia y desobediencia del cuerpo ante lo que le acontece en su historia desde el nacimiento y por esto aparecen síntomas físicos y psíquicos, que indican relaciones con el objeto de la pulsión.

Entonces, ¿qué es el cuerpo para el psicoanálisis? Colette Soler (2010) propone el cuerpo como una realidad, es decir, algo que no está dado de forma primaria; es una construcción, puede surgir y puede no surgir. Es una construcción en un sentido significante, puede haber organismo biológico humano, pero no cuerpo como sistema significante.

El cuerpo es una realidad no primaria; la realidad es una superestructura que surge sobre una estructura que la precede y va más allá de esta: la estructura significante. En otros términos, el cuerpo humano existe antes de venir al mundo en la red de los significantes, por ejemplo, los padres lo nombran, la familia lo espera; al morir también se perpetuará más allá del cuerpo, como palabra y memoria en los otros, o la sepultura que es una permanencia simbólica del cuerpo.

Así, el significante introduce el discurso en el organismo, entonces, estamos separados del cuerpo y podemos prescindir de él. Este margen temporal del lenguaje más allá del cuerpo es lo que Lacan señala como un margen más allá de la vida. Gracias a la separación que introduce lo simbólico entre el cuerpo y el significante, el hombre puede pensar en la separación del alma y el cuerpo, o imaginar la inmortalidad del alma. No obstante, el significante, lo simbólico, no alcanza para dominar al cuerpo; tiene en sí un resto no-subjetivable de real. Pensar esto en relación con la dietética filosófica significa que ninguna recomendación, aunque sea la mejor, basta para ordenar el desorden del cuerpo que escapa a los discursos de la razón.

Como es mencionado en anteriores párrafos, el psicoanálisis busca subvertir algo del discurso médico, devolviéndole al sujeto la posibilidad de preguntar sobre sí. El cuerpo es un real que no se deja dominar; encuentra sus modos de defensa ante el aplastamiento de la subjetividad y por eso aparecen los síntomas. En este sentido, no existe una mejor dietética que la formulada para sí por cada sujeto, aquella descubierta en la observación continua de su cuerpo, de sus pulsiones y su deseo.

En el dispositivo psicoanalítico se constituye esta apropiación del cuerpo, a su vez, la colonización de lo inconsciente en la creación discursiva pues el efecto significante afecta al cuerpo. El objeto de la pulsión no es fijo, es decir, para el sujeto 
del inconsciente no hay un alimento en sí mismo mejor que otro; son elementos significantes para el deseo del sujeto (Alain-Miller, 2012).

La relevancia de retomar la dietética filosófica actualmente reside en volver a preguntarnos sobre nuestra morada; el cuerpo como una constante construcción en el tiempo para nutrir las subjetividades adelgazadas hasta los límites de su desaparición. El hombre es un umbral que recibe y produce estados de sí, de acuerdo con el régimen vital practicado y a las circunstancias en las que vive.

La dietética otorga relevancia reflexiva acerca de cada elemento que conforma la vida: la geografía, su historia, la genética, relaciones familiares y sociales, la alimentación, la práctica del conocimiento, el origen de vida, las actividades corporales... La revolución está en el dominio de sí, punto común en Nietzsche, Plutarco y la ética de la clínica psicoanalítica.

\section{Referencias bibliográficas}

Alain-Miller, J. (2012). Los enredos del cuerpo. Venezuela: Editorial Pomaire.

Bacon, F.(1949) Study from the human body. The National Gallery of Victoria. Recuperado de: https://www.ngv.vic.gov.au/explore/collection/work/3761

Nietzsche, F. (2005). Ecce Homo. Cómo se llaga a ser lo que se es. España: Alianza Editorial.

Plutarco. (2018). Cómo mantenerse sano. España: Me Cayó El Veinte Editorial.

Soler, C. (2010). El cuerpo en la enseñanza de Jacques Lacan. El psicoanalista lector (2007-2020). Recuperado de: http://elpsicoanalistalector.blogspot.com.ar/2010/09/ colette-soler-el-cuerpo-en-la-ensenanza.html 